\title{
Reuse of Abandoned Railways Leads to Urban Regeneration: A Tale from a Rust Track to a Green Corridor in Zhangjiakou
}

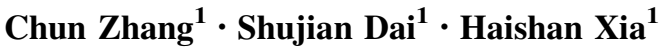

Received: 31 August 2019/Revised: 7 December 2019/Accepted: 31 January 2020/Published online: 9 March 2020

(C) The Author(s) 2020

\begin{abstract}
While high-speed train systems have accelerated mobility in China during the twenty-first century, the train systems of normal speed have gradually been replaced and abandoned, resulting in a "rust belt" in some Chinese cities. The reuse of abandoned railways provides a way to rebuild urban public transit based on the traditional tracks, and is also a way to transform towards urban regeneration of the surrounding neighborhood. Previous studies discussed the possibilities of three perspectives of reusing the abandoned rails: as a new transportation route, as a place for tourism and commerce and as a green corridor for the public. As a case study, this paper selects Zhangjiakou City, which is the terminal of the first railway routes built by Chinese, and explores methods of transformation from rail to urban rail transit. Under the background of the Beijing Winter Olympics of 2022 being partly held in Zhangjiakou City, the old North station and a $10-\mathrm{km}$ rail between the North and South Station have been abandoned since 2014. This paper suggests conversion of the railway into an urban tram to meet the increasing commuter flow between the old and new city center. Additionally, transformation of the abandoned railway located in the city center will also trigger the urban space regeneration by increasing more urban functions and promoting urban public space. This research might shed light on other cities with similar transforming transportation facilities by
\end{abstract}

Haishan Xia

hshxia@bjtu.edu.cn

Chun Zhang

zhangc@bjtu.edu.cn

1 Beijing Jiaotong University, Beijing, China

Communicated by Christopher Auffrey. analyzing the reuse possibilities of Beijing-Zhangjiakou Railway in Zhangjiakou City.

Keywords Reuse of abandoned railways - Urban rail transit · Urban regeneration - Integration planning · Urban decay

\section{Introduction}

Widespread high-speed rail transportation has been a driving force in urban growth in recent years [1] and has also accelerated the speed of inter-city mobility in recent decades [2]. Much previous research has discussed urban expansion driven by high-speed train, especially if located beyond the edge of the city [3]. With the advent of the postindustrial era in China, many of the normal-speed train routes are experiencing decay with the decline of traditional industry [4]. By being replaced with high-speed trains, the normal-speed railway systems in cities have either been adapted to accommodate new needs of the cities [5], or, in many cases, railways have simply been abandoned if they did not fit into the new urban structure of the post-industrial city [6]. There are hundreds of abandoned railway lines in China, which covers about $20,000 \mathrm{~km}$ of abandoned tracks [7].

The abandoned railways are often located in urban centers and might have negative effects on the urban environment. They impact land development, traffic flow, the ecological environment, and quality of life. Transportation planners usually refer to abandoned railways as a cause of traffic congestion because they block traffic and divide urban space [8]. Other researchers find that abandoned railways cause lower property values and less new development, and are often an urban blight that results in a 
poor-quality urban environment nearby [9]. In many cities in China, these abandoned railways are often ignored and left there [10]. In some extreme cases, abandoned railways have also become a potential driving force of urban decay, especially around old and dilapidated housing areas.

However, in terms of the potential value of abandoned railways, their reuse would be a benefit to the local neighborhood [11]. Although abandoned, railways usually occupy prime city real estate. Besides, if being used reasonably, the linear physical space in the city center would be an important connector that increases the linking possibility of functional nodes along the railway line [12]. So the disused tracks could be also regarded as important cultural heritage as a reflection of industrial history, and also the rise and fall of cities [12]. Globally, there are some successful cases of redeveloping abandoned railway stations and tracks into museums; for example, Union Station Terminal in Cincinnati, and the NC Transportation Museum in North Carolina, United States.

From the 1990s to the beginning of the twenty-first century, a large volume of literatures on urban regeneration have discussed the renewal of residential communities in China [8]. The majority of research focuses on residential relocation of the low-income neighborhood in inner city, echoing the Western re-gentrification theory and criticizing the urban redevelopment tendency to "swipe the poor away." While the location advantage of inner cities has been realized, research on how transportation infrastructure leads to redevelopment has not yet been sufficiently studied. Besides, most urban transformation theory and urban regeneration theory also focuses on the physical renewal of residential neighborhoods [13, 14]. The simple renewal of physical space cannot trigger the urban regeneration effectively. However, bearing in mind the advantages of location and the mobility of transportation infrastructure, how to trigger urban regeneration through the reuse of abandoned railways will be an important perspective of this study.

Therefore, the first section of this paper will explore different ways of reusing abandoned railways based on a review of the literatures. In the twenty-first century, improving urban mobility might play a more important role in global urban renewal. The structure of this paper is as follows: The first section discusses the benefits of different reuse modes on urban environment [15], and what kind of urban environment different regeneration modes adapt to. In the second section, the case study of the BeijingZhangjiakou Railway (Fig. 1) located in Zhangjiakou City will be studied as an example to discuss how to integrate three modes on the same railway.

\section{Research Progress on the Reuse of Abandoned Railways}

From the points of previous literatures, reuse modes of disused railways have mainly been divided into three types: as traffic facilities, as places of tourism and commerce, and as public space for citizens. The research framework of rail transportation leading to urban regeneration is summerized in Fig. 2 and the reuse modes are described in detail after Fig. 2.

\subsection{The Reuse Strategy of Abandoned Railways as Traffic Facilities}

Many scholars focus on the potential opportunity in reusing abandoned railways as new transportation facilities in cities. It is often suggested that the abandoned railways could be transformed into urban rail transit systems, including light rail, urban tram lines, suburban railways, or urban roadways with a combination with the existing transportation network. Many urban railways had been constructed along with the cities, such that they are always located in the center area with a relatively high density population. Retaining the transportation function and serving the surrounding neighborhoods might be one of the effective strategies for the reuse of abandoned railways.

A case often referred to in China is the abandoned railways in Binhai District in Tianjin City [16]. It has been proposed that the existing railway track will be transformed into light rail lines to create new railway networks for improvement of traffic conditions in newly developed areas in Tianjin City. It would form a suburban railway pattern called "one ring and three lines" in Tianjin. Another case study in China illustrated how to reuse abandoned track of the former Zhejiang-Jiangxi Railway line abandoned in Shangrao City [17]. It has been proposed that some abandoned lines could be reserved for future urban rail transit construction, while others could be planned for urban development. Similar study of the abandoned Zhejiang-Jiangxi Line focused on the Yiwu section of the railway [8]. Conversion of the abandoned railway into a tram line has also been proposed, based on the status of the current urban transportation system, forecasts of urban growth in the city, and future transportation demands. In other research, Eizaguirre-Iribar et al. [18] proposed the traffic potential of abandoned railways as bike lanes; their study explored non-motor vehicle accessibility of linear railway infrastructure at different scales.

In addition to abandoned lines, researches have also focused on how to redeveloped the area surrounding old railway lines. For example, a study by Shen [12] on 

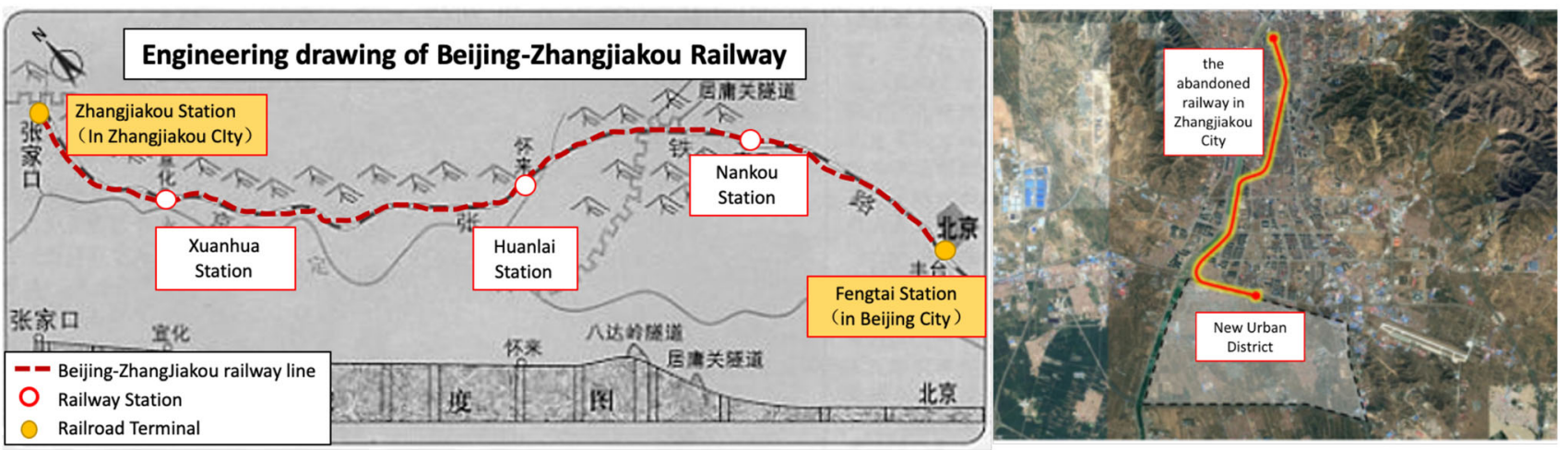

Fig. 1 Beijing-Zhangjiakou Railway line (left); the abandon railway in Zhangjiakou city (right). Source: Drawn by the authors

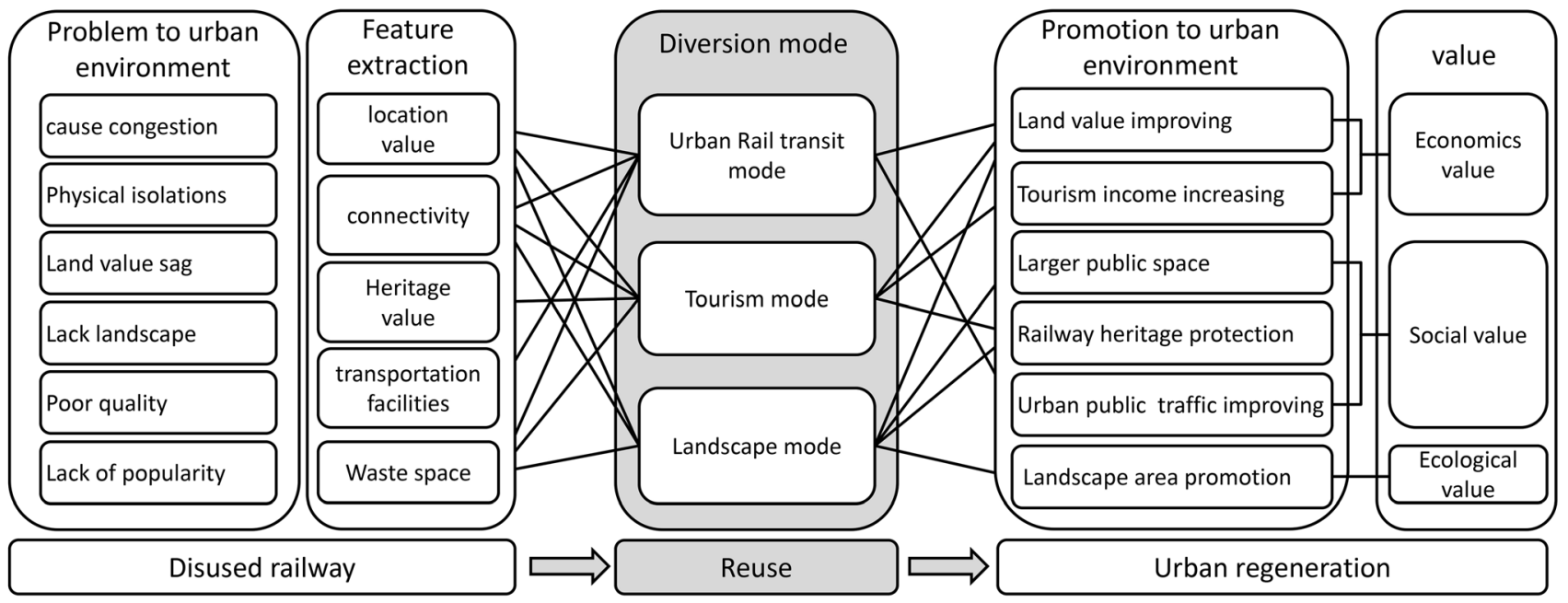

Fig. 2 The research framework of rail transportation leading to urban regeneration. Source: Drawn by the authors

developing an urban rail transit from abandoned railways emphasizes the necessity of converting abandoned railways in suburbs to revitalize the neighborhoods. The feasibility of funding, reuse techniques, and transportation modes also need to be carefully considered. Similarly, considering the various aspects of railway systems, technology, and implementation modes [19], recommendations that the abandoned railway should be reused as a new urban transit network have also been made. Another study on transformation from existing railway lines in cities to modern trams analyzes the possible transformation modes: such a trams, bus lanes, and bike lanes [20].

\subsection{The Reuse Strategy of Abandoned Railways for Tourism and Commercial Development}

There are also some successful cases of reusing abandoned railways for tourism and commercial functions. As the heritage of industrial culture, abandoned railways have also become a place of interest. For example, in Paris, the Osei Museum was transformed from a railway station that had been abandoned for many years. The Puffing Billy Railway in Australia and the Jiji Town Railway Tour Line in Taiwan are famous for reuse as tourism routes. In the case of the Hijaz Railway in the Middle East, it was suggested that reuse plans should take advantage of the historical value as well as the linear advantages that are inherent in railway lines [21]. The Hijaz Railway Line was restored as a tourist route which preserves an important part of Islamic culture. And along the repurposed line, historical museums and major tourist attractions were created. Li et al. [22] studied the cultural and technological influence of historical buildings along the Middle East Railway Trunk Line in China, as well as the relationship between buildings and the characteristics of society and culture in the region, so as to provide reference for the protection of historical and cultural buildings along the Middle East Railway Trunk Line.

In China, many areas along abandoned tracks have been transformed into featured cultural and commercial centers, such as Qianmen Street in the old city of Beijing. In these cases, unused land along the disused railway track redeveloped as cultural tourist and commercial projects has 
become an integral part of the urban functions and brings economic benefits for the city. In the literature on the Virginia Creeper Rail Trail, the study focused on reconstruction of the Virginia Creeper Trail (VCT) from abandoned railways in the United States. Bowker et al. [23] tracked and estimated its direct, indirect, and inductive effects on the local economy. This study has shown that VCT railway lines were valuable not only for the tourism industry, but also as a means of stimulating the growth of the regional economy. In another article, Betz et al. [24] created an accidental travel model to estimate the tourism industry and the value of a potential rail track site in northeastern Georgia. It estimated that 416,213 families would visit the recreational facilities each year. A study on the reuse of abandoned railway corridors in the archaeological area in Italy [25] proposed that sustainable renewal should take the particularities of specific sites into account and make full use of them to re-establish the railways to meet the needs today. Australian scholars [26] evaluated the development of abandoned railway lines in Australia for cyclists. They proposed that long-distance railway tracks require careful planning and design in terms of service facilities and infrastructure.

\subsection{The Reuse Strategy of Abandoned Railway as Urban Public Space}

As for the regeneration of abandoned railway as green public space, some scholars discussed it from the perspective of ecological value and landscape design, while others emphasized how the reuse result promotes the urban life quality for people. Worldwide, the most common ecological reuse strategy has been transforming abandoned railways into multipurpose trails for walking, cycling, horse riding, ice skating, and other similar usage. In the United States, a highly successful program known as Railsto-Trails has converted many abandoned railways into parkways. The Rails-to-Trails Conservancy is a nonprofit organization which advocates for transforming abandoned railways into parkways which have been used widely throughout the United States. The most famous project in the United States has been the High Line Park in New York, in which the abandoned elevated freight railways were converted into a high-line parkway for pedestrian usage, causing a surge in new urban development and in nearby property values along the route. The High Line Park became an important landmark in New York City. Subsequently, the Rails-to-Trails program has spread to Europe, Asia, Australia, and so on. In Australia, Germany, the United Kingdom, Spain, Belgium, and other countries, hundreds of greenways have been created from abandoned railways, forming greenway networks for cyclists and pedestrians all over the world (Rail to Trails, 2019).
There are two representative cases of redeveloping abandoned railways [27, 28] into greenways in Portugal and Italy. Both of them concluded that the purpose of the greenway is not only replacement of the abandoned railways, but to create a positive connector of urban important function nodes which serves to promote economic development and improve urban public life. Ferritti and Degioanni [29] proposed a variety of feasible reuse solutions for an abandoned railway in the Piedmont Region. They pointed out that reuse of abandoned railways involves multiple economic, environmental, and social factors. It also involves different stakeholders. Learning the multiattribute value theory (SAVT), they evaluated the psychological goals of comprehensive stakeholders and offered measurable quantitative assessment schemes to determine the best ways of transforming the abandoned railway. A post-event analysis(PFA) model [29], an analytic network process (ANP) method [30], zero-one goal programming (ZOGP) [31] and an indicator system for sustainability [32] have been used for a comprehensive assessment to determine the optimal reuse solution of abandoned railways.

\subsection{Analysis of Three Main Reuse Strategies in Terms of Urban Promotion}

The above literature review provides three transformation modes: as transportation facilities, as a place for commercial and tourism redevelopment, and as a public space. This paper will complete the following two tasks: on the one hand, it will analyze application scope of the three modes, in order to select the most suitable transformation mode for actual cases. On the other hand, it will compare the main improvements on surrounding urban space by the three modes, so as to determine how to combine the positive impact of these three modes in the following case analysis.

In a short, the issues of urban abandoned railway redevelopment enrich the current urban renewal theory from the perspective of urban mobility. The transportation mode is most appropriate for areas with a high demand for public transportation along the railway routes. A new efficient transportation infrastructure will contribute to improving the public transport situation and increase land value. The business and travel redevelopment mode is most applicable to nearby railways or destinations having significant cultural significance, in cities with strong tourism industries, or areas with a strong commercial environment. It will help redevelopment and increase both tourism income and land value by maintaining the old tracks and stations. The urban public space mode is most suitable to areas lacking public green space. Urban green space and greenways created from abandoned railways become public urban space in the city, 
providing green space to residents and connecting municipal public service nodes. Studies have shown that the transformation of abandoned railways into parks and green belts has not only improved the urban environment, but also increased surrounding land prices for housing. Table 1 shows an evaluation of the impacts that different transformation modes have on urban public space, land values in proximity to railway lines, the ecological landscape, tourism revenues generated by conversions, and transportation advantages generated by the railway conversions.

\section{Case Study of Beijing-Zhangjiakou Railway in Zhangjiakou City}

Beijing- Zhangjiakou Railway is the oldest railway constructed by Chinese in railway history. However, the abandonment of this railway is accompanied by the decline of the surrounding urban space quality. The forthcoming Winter Olympic Games (2022) in this city has inevitably brought new demands for urban planning and transportation infrastructure construction. This case is about how to explore the potential of the railway from the future needs of the city, and reuse the railway correctly with the conclusions of the above research.

\subsection{The Past: the Role the Railway Plays in the City}

The Beijing-Zhangjiakou Railway has an important historical significance in Chinese history. It was the first railway designed and constructed by Chinese engineers and techniques without help and cooperation. And it has existed for more than 100 years. Besides, Beijing-Zhangjiakou Railway used to be the main trading routes connecting Beijing, the capital of China, with Mongolia, and finally to Kiyaytu (Хяагта) in Russia as the ancient merchant route. Some railway sections across Zhangjiakou City, which is located to the northwest of Beijing City, became a transportation hub connecting Beijing with Mongolia and Russia.
The section of railway in Zhangjiakou City is referred to as the "City Life Line of Zhangjiakou." Since it was selected as a heavy industry center in Northern China during the first 5-year plan period (1949-1954), many modern industries took roots in Zhangjiakou. Besides, many industrial plants had been established along the railway with working-class housing distributed around the factories since then. Subsequently, with the rapidly development of heavy industry, Zhangjiakou had been transforming from a traditional commercial city into an industrial city after the foundation of the People's Republic of China in 1949.

Spatially, urban expansion of Zhangjiakou city had been closely related to this railway [33]. The railway brought merchants, freight, and materials from other cities of China to Zhangjiakou, and catalyzed the creation of a new commercial center near Zhangjiakou North Station [34]. As Fig. 3 shows, before the construction of the BeijingZhangjiakou Railway in Zhangjiakou, there were two principal centers in the city: the Laiyuan Fortress, famous for Sino-Mongolian trade, and the Puzili Fortress, constructed for the military. The completion of the railway in 1909 caused a relocation of the city centers from the west area of the Qingshui River to the east area of the Qingshui River.

\subsection{At Present: The Decline of the Old Railway Section}

Both the transfer of the regional commercial center and the decline of heavy industry resulted in the decline of Zhangjiakou City and the railway line. In the 1970s, the opening and development of the southern coastal areas in China led to the transfer of the economic center from Northern China to Southern China. As an important commercial road in the past, the corridor connecting Zhangjiakou City with Mongolia and Russia had been declining into decay gradually. In addition, in the 1990s, the adjustment of the national economic structure from heavy

Table 1 Main impact of different transformation modes on the urban environment. Source: Drawn by the authors

\begin{tabular}{llll}
\hline Reuse strategy of abandoned railway & Transportation mode & Business and travel redevelopment mode & Urban public space mode \\
\hline Promotion to urban environment & & & $\sqrt{ }$ \\
Urban landscape area promotion & $\sqrt{ }$ & $\sqrt{ }$ & $\sqrt{ }$ \\
Improve public transport situation & $\sqrt{ }$ & $\sqrt{ }$ & $\sqrt{ }$ \\
Increase land value & & $\sqrt{ }$ & $\sqrt{ }$ \\
Increase tourism income & & $\sqrt{ }$ & \\
Larger public space & &
\end{tabular}




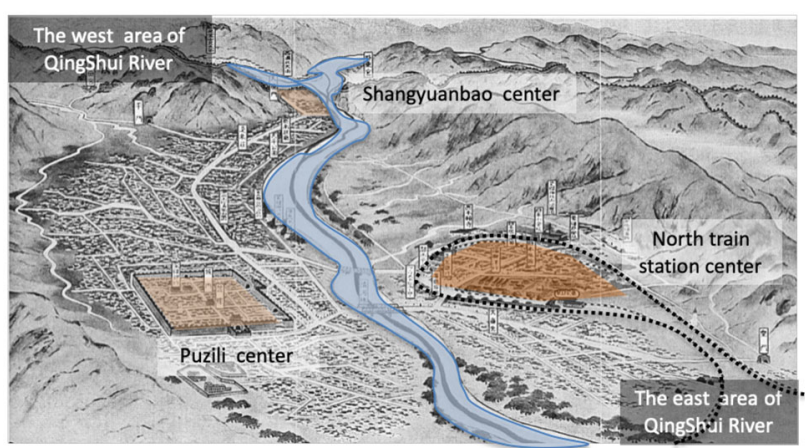

Fig. 3 A new commercial center was formed near Zhangjiakou North Station. Source: Drawn by the authors

industry to light industry made Zhangjiakou, who had developed as a heavy industry city, go downhill.

At the same time, with the expansion of the city, the railway and the station are gradually situated in the center of the city, and noise and air pollution of trains gradually had a negative impact on the surrounding residents. A new Zhangjiakou South Station as a high-speed train station began to be built in 2017. The development of the Zhangjiakou South Station has led to the expansion of cities around the South Station, and gradually shifted the urban development center southward. The new urban area has been formed with the old urban center gradually declining. With the closing of Zhangjiakou North Station, the abandoned railway section between the previous Zhangjiakou North Station and the new Zhangjiakou South Station also became abandoned. The abandoned section of the Beijing-Zhangjiakou Railway is about $10 \mathrm{~km}$ long and runs through the former downtown area of Zhangjiakou.

The abandoned railway became a "scar" for the city (Fig. 4). Firstly, the area along the track is filled with dilapidated housing and less maintained facilities. The poor spatial quality of the urban landscape along the railway affects the spatial quality of working-class neighborhoods along the line. Secondly, not only the track is abandoned, but also the old station and factories are idle. Last but not least, the improper distribution of traffic facilities along the line often causes traffic jams in the north-south direction of the city.

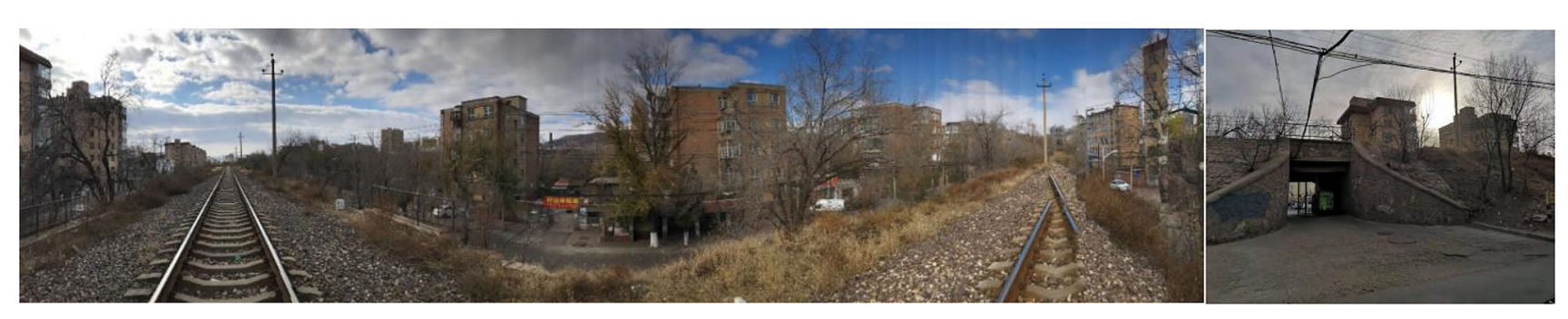

Fig. 4 Environment along the abandoned railway. Source: Drawn by the authors

\subsection{The Future: The Analysis of Regeneration Potential along the Abandoned Railway}

The abandoned railways and adjacent urban space have much potential for redevelopment, as transportation facilities, for tourism and commercial purposes, or as urban parks. Redevelopment will be discussed in three respects: transportation potential, business and tourism redevelopment potential, and urban public space potential (Fig. 5).

From the perspective of transportation potential, the abandoned railway passes through the important traffic points of the city. It runs along the main passenger corridor in Zhangjiakou City between Beijing South Railway Station and Zhangjiakou North Station. It connects the highspeed rail station to the city center and could also be extended to the tourism area in the northern part of the city, as well as to the airport in the eastern area of the city. Besides, the successful bid for the Twenty-fourth Winter Olympics in Zhangjiakou in 2022 will bring greater passenger flow to the city. It is predicted that the total number of trips in 2030 will be 1.98 billion, double that of 10 years ago, which also implies more potential passenger flow of the line in the future.

As for land redevelopment potential, urban land along this railway line is mixed with a variety of urban functions, such as residential area, commercial area, and universities. The renewable land area along the line is more than 1 million square meters. There are also abandoned industrial buildings and historical heritage with cultural value along the railway line, including the Zhangjiakou North Station-"A-Hundred-Year-History-Station"-and the famous old factory of Zhangjiakou, Zhongdi Equipment Exploration Engineering Machinery Co., Ltd. The shops near the North Station are well developed with many large, upscale shopping mall complexes, such as the Baisheng Shopping Mall.

When discussing the potential of the railway line as urban public space, there are more than 600,000 people living or working near the area within $1 \mathrm{~km}$ of the railway. Half of the abandoned railway section is close to the urban ecological landscape Qingshui River, so that it enjoys a good view of the waterfront. Because both east and west sides of the city are surrounded by mountains, the east- 


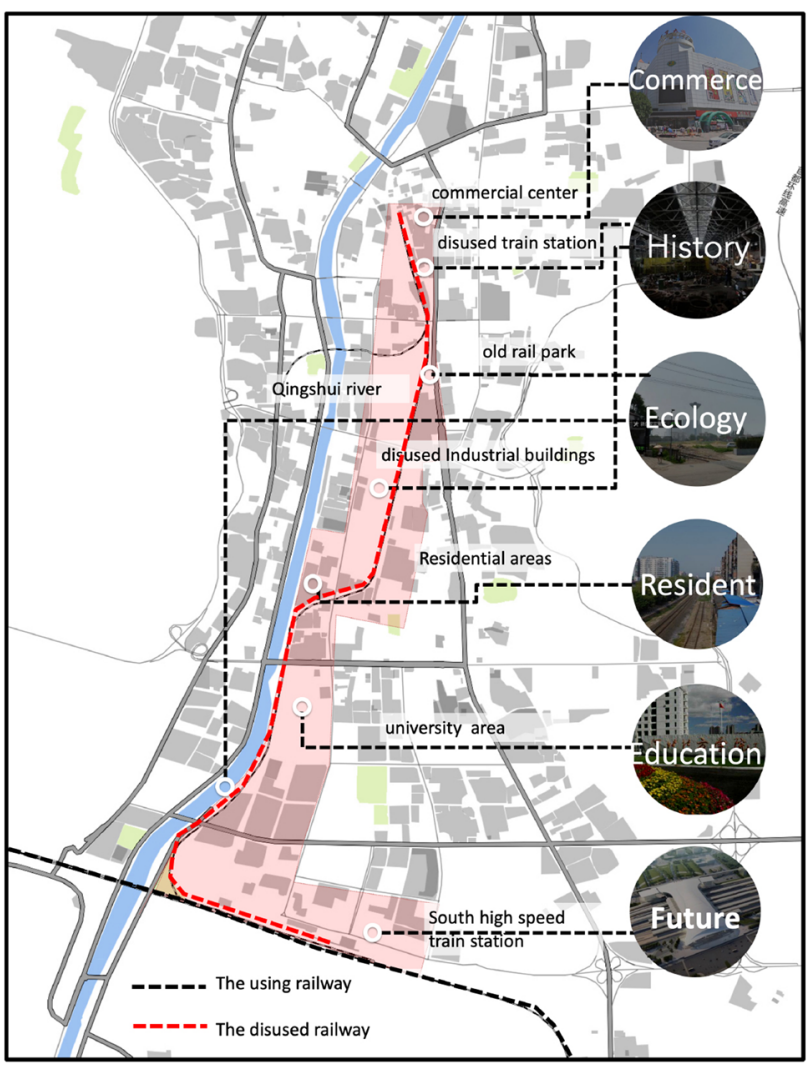

Fig. 5 Resources along the abandoned railway. Source: Drawn by the authors

west urban roads along the railway can enjoy the mountain scenery. Besides, there are several public green spaces along the railway, such as Zhangjiakou Sports Park in the high-tech zone, Nankou Park, and green space in the university campus along the line.

\section{Urban Space Regeneration Design Strategy Along the New Line}

For the purpose of reusing the railway line and urban space, three urban space regeneration design strategies of urban traffic, land regeneration, and urban public space were proposed. First, by borrowing international experience of "rail to tram," we suggest converting the abandoned railway line to an urban tram line to meet the city's future development and transportation needs. Then, on the basis of the current urban planning, the strategy of redevelopment of the land along the abandoned railway will be proposed. Finally, aiming at the problem of lacking public space in Zhangjiakou that used to be an industrial city, it will put forward the suggestion of transforming the rust track to a green belt.

\subsection{As Transportation: Disused Rail to New Tram}

The current transportation system in Zhangjiakou City has not met the future traffic growth demand. The disused railway line and its extension line are connected with the main passenger distribution center, including the highspeed railway station, airport, center area, and so on. This line can be defined as one of the principal passenger corridors in Zhangjiakou City.

At present, buses handle the majority of public transportation capacity in Zhangjiakou City. Transforming the abandoned railway line into an urban rail transit line can greatly expand the capacity of the public transportation system in Zhangjiakou. It will be helpful to the tourist industry for Zhangjiakou City as well. Compared with other municipal public transportation modes such as buses, urban rail transit cannot only retain the original rail form of the city, but also have the advantage of large traffic volume. Therefore, it is necessary to re-plan the line as an urban rail transit line to solve the problems of internal public transportation and external tourism transportation of Zhangjiakou City.

Borrowing international experience of "rail to tram," we suggest converting the abandoned railway line to an urban tram line to meet the city's future development and transportation needs (Fig. 6). Table 2 shows the characteristic of four possible urban metro systems. When selecting the possibility of urban metro system, the tram shows its advantages in the following aspects. Compared with other systems, it has the advantages of moderate speed and low cost. It costs only 80-150 million Chinese Yuan per kilometer. And the tram system has the highest speed of $70 \mathrm{~km}$ per hour. Since the abandoned line is only $10 \mathrm{~km}$ long, the tram system will allow a tram stop at every $1000 \mathrm{~m}$.

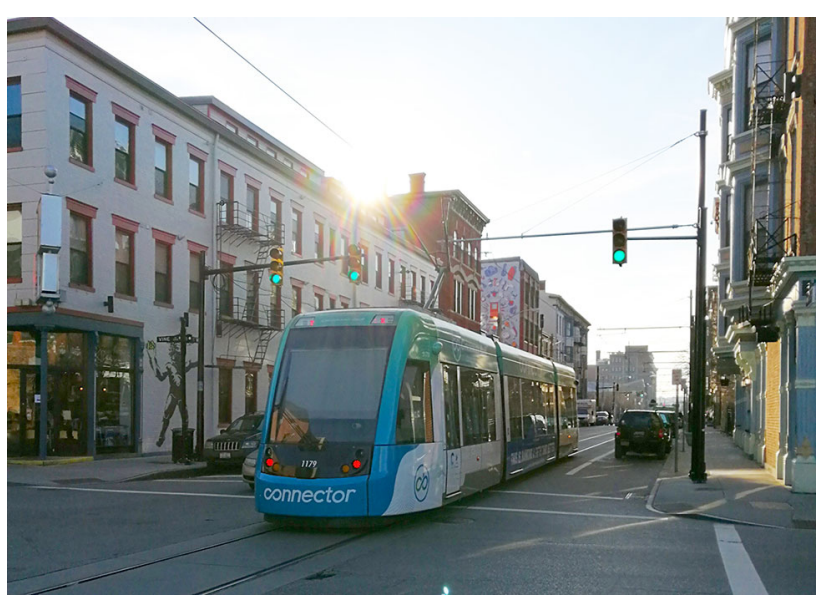

Fig. 6 The tram line in the city. Source: http://www.gzmtr.com 


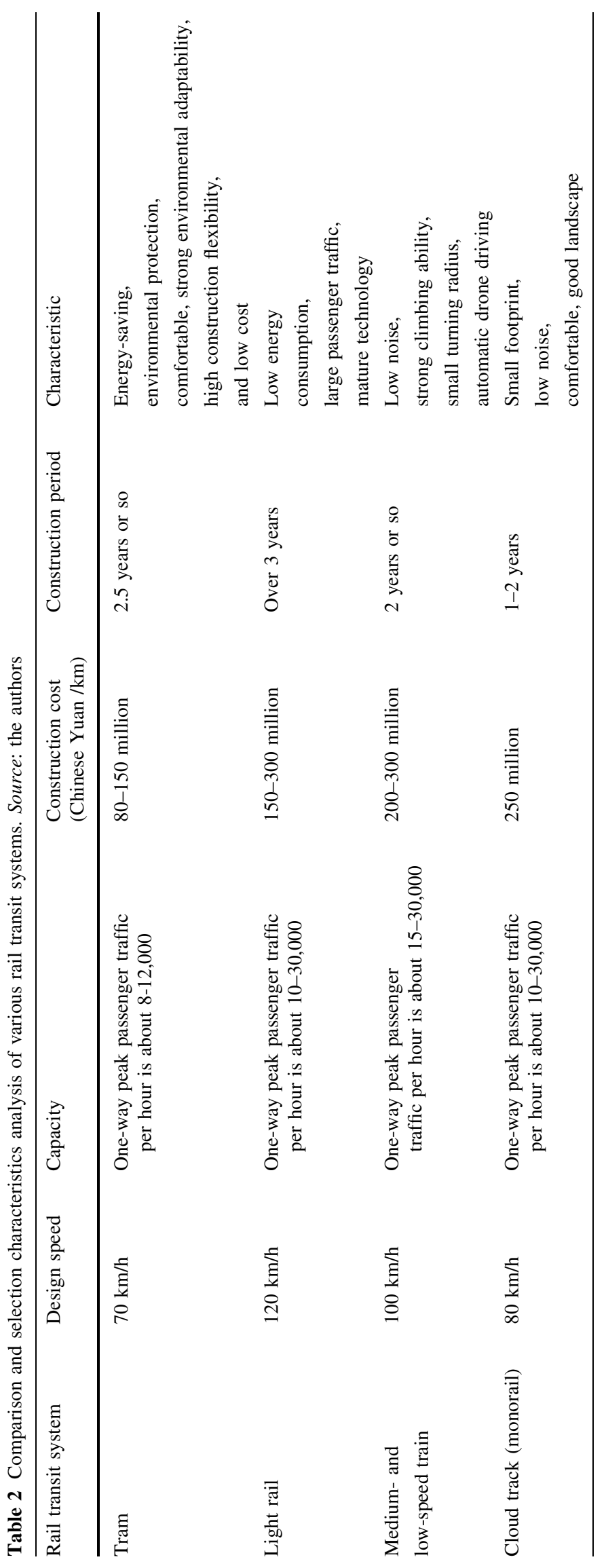


If this is done, the tram line could handle more than half of the public transport volume along the line. Five buses pass the railway, with a maximum total capacity of about 46,000 people per day. The tram line from Nankou Park to Zhangjiakou South Station can carry more than 30,000 passengers every day.

\subsection{As Places for Tourism and Commercial: Area Function Activation}

The placement of trams will inevitably bring economic growth and bring new development to the city along the line. Based on the new tram line, creating new function nodes along the railway line will positively impact the surrounding urban environment and link the development of dynamic urban economic networks. The previous urban planning fails to define the urban land along the line, which makes the regional function of the urban area lack characteristics.

As shown in Fig. 7, based on the different characteristics of each part along the railway, the area has been divided into five parts from north to south. The first district at the northern end of the line is considered to be railway commercial and tourism district. At present, the district is characterized by a strong commercial atmosphere. The historic building North Railway Station is located in the

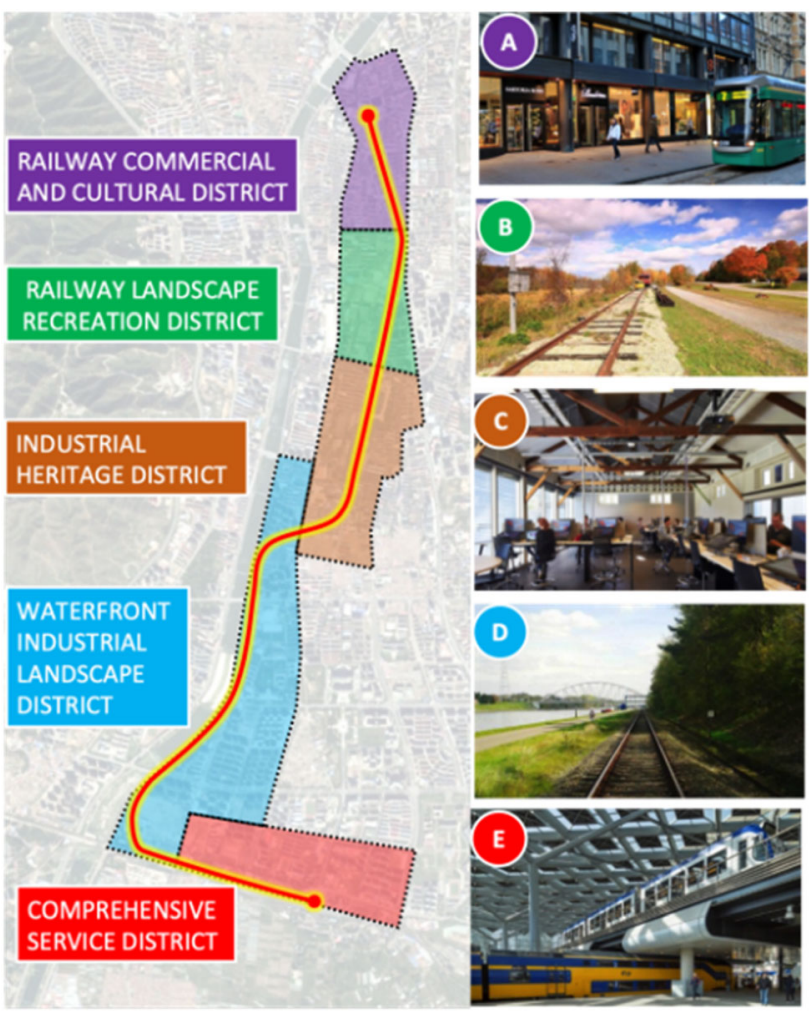

Fig. 7 The renewal district along the railway. Source: Drawn by the authors area A transformation from a disused station to a tourist attraction for the purpose of evoking historical memory and promoting the tourist industry as a viable option for this area. The area further south is classified as a the railway landscape recreation area where the banded abandoned area could be redesigned into a green belt. And the disused track would be treated as a landscape decoration. The main project in this area is the regeneration of the existing Railway Memory Park, which is underutilized and lacks pedestrian accessibility. The design of the new park could embody the evolution of time from the "normal rail era" to the "high-speed rail era" to create an urban pedestrian public space for citizens in Zhangjiakou. The third area is the "industrial heritage area" with a legacy of the former industrial housing. For tourism, the old industrial plants with large space are suggested to be transformed into a railway memory museum to display the historic materials of the Beijing-Zhangjiakou Railway, Jeme Tian You (the engineer of the railway), and railway history in China. The other former industrial buildings could be converted to work space or creative studios for entrepreneurs and artists. Based on these antique buildings, some characteristic stores could also be set up, not only serving tourists, but for nearby residents and workers. The main waterfront landscape is located in the fourth part of the area along the railway. It is called the "waterfront industrial area" which could combine the waterfront landscape with the railway landscape to create an exceptional urban public space for walking and jogging. Some special outdoor business or containers with commerce facilities could be created. The southernmost area is classified as a "comprehensive service area" mainly serving transportation and commercial needs. Zhangjiakou High-speed Railway South Station is proposed to be an integrated transportation hub serving a large capacity of people with various connection options. The passengers would easily transfer to the new tram line from Zhangjiakou High-speed Railway South Station in this area.

Because road characteristics depend on different urban functions, road profiles of some parts of urban space along the new tram are to be redesigned. In the railway commercial and tourism areas, the track of the tram shares the right of way with the urban carriageway. The tram in the railway landscape recreation area passes through the railway park. Pedestrian traffic could be created on both sides of the tram which will promote the accessibility of tram stops (sees Fig. 8). The tram subgrade in the industrial heritage area was widened on the original slope so that a double-track railway could be used. The slope and tram will become an impressive and pleasant elevated landscape in the city. In the waterfront industrial landscape area, the tram can run alongside the river for passengers to enjoy the riverside landscape. 

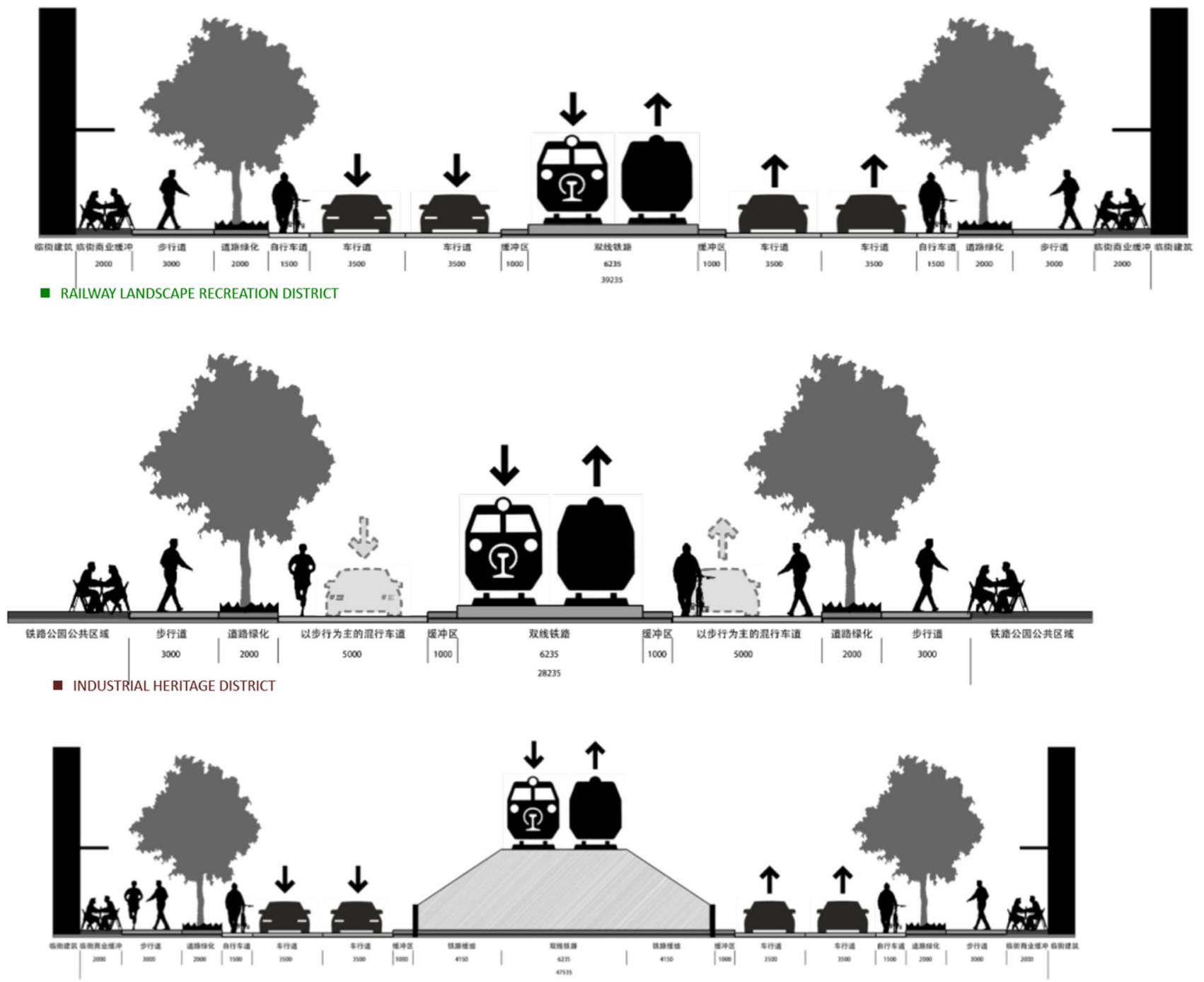

Fig. 8 Redesign of the roads along the railway. Source: Drawn by the authors

\subsection{As Public Space: Rust Track to Green Belt}

As mentioned above, the appearance of a new tram and a characteristic functional area endows the city with new public space, such as the new commercial and tourism street around the old North Station for strolling and shopping, the new green pedestrian areas along the tram line and river for wandering, the new railway museum for free visiting to the new square in the cultural and creative park for staying for a while, and so on.

Public space in Zhangjiakou was composed of open space in large- and medium-sized enterprises and shared space in small residential communities in the past. As a former industrial city in the north of China, Zhangjiakou City lacks public space for citizens to spend their spare time. By creating a series of urban functional nodes along the line, redesigning a variety of urban streets for walking and jogging, and increasing the area of urban green space, the space created along the railway line can be integrated into an urban public space system in Zhangjiakou City. The new public space system consists of urban public square, urban pedestrian roads, urban green space, and other types of public space.

Public urban nodes connected by the railway are not only the carriers of urban function, but also places where urban public activities take place. Relying on various types of public space, urban public activities such as ice and snow sculpture festivals, railway cultural exhibitions, Winter Olympics-themed city tours, and temple fairs in the railway business and tourism area could be planned along 


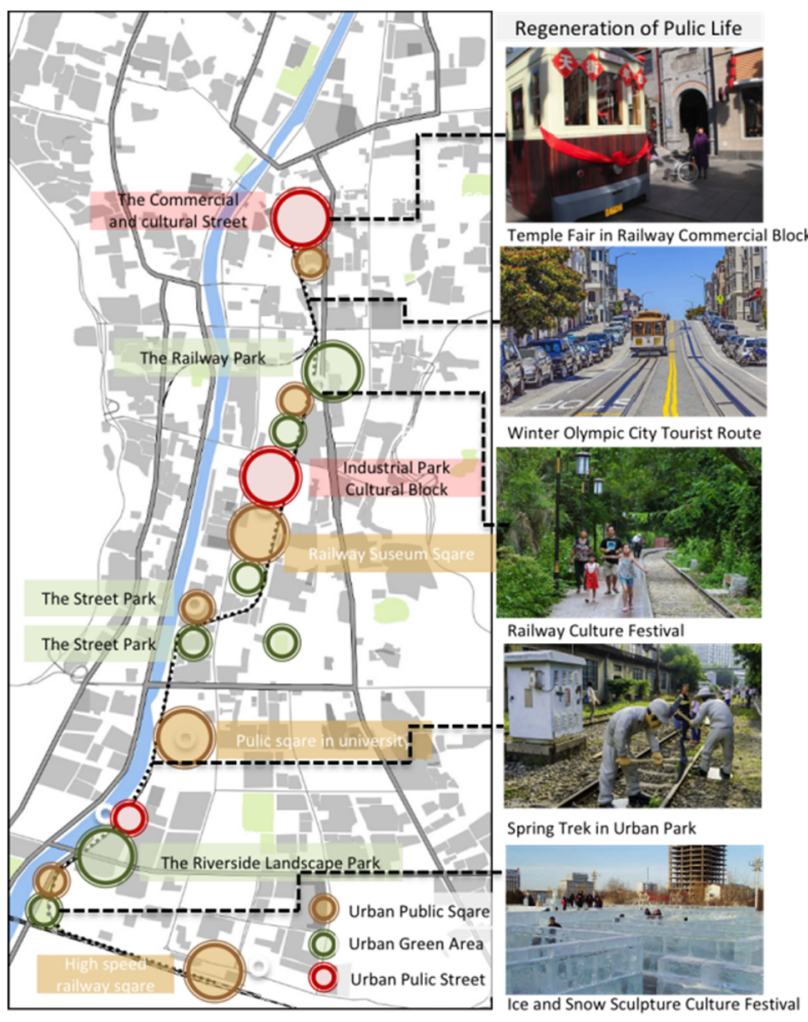

Fig. 9 The regeneration of public space and public life. Source: Drawn by the authors

the newly designed line to encourage more outdoor activities (Fig. 9).

\section{Discussion and Conclusion}

Abandoned railway space is a negative space in city, causing many adverse effects to the surrounding areas. However, this is a very common situation in cities because the needs of cities are constantly changing. When the railway loses its original function, the reuse of the abandoned line can revitalize the urban area. We also can plan for the future needs of the city.

Three common strategies for reusing railways include converting them into new rail transit systems, or redeveloping the urban land around them for business and tourism purposes, or shaping new public space systems for the city. It has been proved that different reuse strategies will have different positive effects on urban space, including the improvement of traffic conditions, the opportunities for land development, the growth of tourism income, and so on. However, different transformation strategies are suitable for different actual cases. Facing different actual situations, we should consider how to use them, or even how to integrate the positive effects of the three strategies on the surrounding environment into one case.
Under the background of urban regeneration, most researches focus on the physical environment renewal of a residential area in cities, with limited discussion on renewal of urban transport infrastructure [35-37]. However, urban transportation facilities renewal has become increasingly important in contemporary cities, considering their prime location, historical value, and relation to innercity neighborhoods. It is not enough to focus on the renewal of the physical environment [38-40]. The renewal of traffic infrastructure can meet the urban requirements of mobility and connectivity [41]. This paper enriches the content of urban regeneration from the perspective of transport infrastructure regeneration. The practice of reusing urban disused transport infrastructure has just begun, and there is no mature theoretical guidance. This paper presents some theory about how to reuse disused railways for the purpose of urban regeneration and integrate the multiple reuse strategies to trigger urban regeneration. The Zhangjiakou section of Beijing-Zhangjiakou Railway is taken as an example to prove the feasibility of the theory.

Acknowledgements This study was supported by the National Natural Science Foundation of China (51678029).

Open Access This article is licensed under a Creative Commons Attribution 4.0 International License, which permits use, sharing, adaptation, distribution and reproduction in any medium or format, as long as you give appropriate credit to the original author(s) and the source, provide a link to the Creative Commons licence, and indicate if changes were made. The images or other third party material in this article are included in the article's Creative Commons licence, unless indicated otherwise in a credit line to the material. If material is not included in the article's Creative Commons licence and your intended use is not permitted by statutory regulation or exceeds the permitted use, you will need to obtain permission directly from the copyright holder. To view a copy of this licence, visit http://creativecommons. org/licenses/by/4.0/.

\section{References}

1. Zhang N, Xu Y (2005) Research on the impact of high-speed railway on regional development along the line. Reg Res Dev 24(3):32-36

2. Xia H, Liu X, Zhang C (2018) Theoretical research and development trend of contemporary urban rail transit integrated hub. World Archit 4:10-15

3. Li C, Meng L, Zhang T (2018) Comparative study on the impact of railway multi-stations on urban spatial structure. Int Urban Plann 6:36-42

4. Zhang F, Yang W (2017) Selection of utilization modes of urban waste railways based on value engineering. J Heilongjiang Inst Eng 31(4):12-18

5. Jin F, Wang E (2004) China railway network expansion and spatial accessibility in the 20th century. J Geogr 59(2):293-302

6. Lin W (2018) Research on activation and utilization of urban abandoned railways. In: Sharing and quality-2018 China urban planning annual conference paper collection (02 Urban Renewals), pp 509-522 
7. Zuo Z, Li C (2017) Study on the construction and planning of high-density urban ecological pattern based on the reuse of abandoned urban railways. Urban Archit 21:37-40

8. Wu X, Jiang L (2005) Turning the abandoned railway line into an urban expressway-take the Yiwu Line transfer in the electrification reform of Zhejiang-Jiangxi Railway as an example. Planner 21(s1):43-46

9. Wang J, Xiang Y, Luo Y (2010) Urban abandoned railway planning strategy based on the concept of green corridor. Northern Horticult 5:129-132

10. Ma Y, Jiang H, Bian Y (2015) Landscape path of abandoned railway in Kwangzhou Greenway Park, Korea. Ind Build 10:65-68

11. Geng H (1999) Dynamics of urban renewal in China. Urban Plann Bull 3:27-31

12. Shen $J$ (2012) Research on the function of urban rail transit in idle railway hubs. Railway Stand Des 1:10-14

13. Wu L (1994) The old city of Beijing and its Ju'er Hutong neighborhood. China Architecture and Building Press, Beijing

14. Acharya SK (2005) Urban development in post-reform China: insights from Beijing. Nor Geogr Tidsskr 59(3):228-236

15. Syms P (2000) Urban regeneration: a handbook. Reg Stud $34: 896-897$

16. Wang X (2014) Discussion on transformation of idle railway of Tianjin hub into urban railway planning. J Railw Eng 3:19-24

17. Huang $X$ (2014) Utilization analysis of abandoned corridors along the former Zhejiang-Jiangxi Railway in Shangrao City. Transp Transp Acad Ed A01:143-146

18. Eizaguirre-Iribar A, Etxepare L, Rufino JHM (2016) A multilevel approach of non-motorised accessibility in disused railway systems: the case-study of the vasco-navarro railway. J Transp Geogr 57:35-43

19. Ma Q (2007) Feasibility analysis of railway conversion to urban rail transit-taking spanish experience as an example. Int Urban Plann 22(3):79-84

20. Wang Z, Wang W (2012) Discussion on the renovation of modern trams for special branch lines of existing urban railways. Modern Urban Rail Transit 5:11-15

21. Olendzki A (2008) A railway 'route' as a linear heritage attraction: the Hijaz railway in the Kingdom of Saudi Arabia. J Heritage Tour 3:159-175

22. Li G, Xu H, Liu D (2014) Interpretation of middle east railway architectural culture communication from the perspective of cultural line. J Archit S:45-51

23. Bowker JM, Bergstrom JC, Gill J (2007) Estimating the economic value and impacts of recreational trails: a case study of the Virginia Creeper Rail Trail tourism economics. Tour Econ Bus Financ Tour Recreat 13(2):241-260

24. Betz C, Bergstrom J, Bowker JM (2003) A contingent trip model for estimating rail-trail demand. J Environ Plann Manag 46(1):79-96
25. Sun J, Yao P (2015) Industrial spatial transfer, regional specialization and coordinated development in Beijing, Tianjin and Hebei: an analytical framework based on new economic geography. Nankai J 1:81-89

26. Willard P, Beeton S (2012) Low impact experiences: developing successful rail trail tourism. Tour Plann Dev 9(1):5-13

27. Jo S (2002) The geography of "disused" railways: what is happening in Portugal? Finisterra Revista Portuguesa De Geografia 74:55-71

28. Oppido S, Ragozino S (2014) Abandoned railways, renewed pathways: opportunities for accessing landscapes. Adv Eng Forum 11:424-432

29. Ferretti V, Degioanni A (2017) How to support the design and evaluation of redevelopment projects for disused railways? A methodological proposal and key lessons learned. Transp Res Part D Transp Environ 52:29-48

30. Ciomek K, Ferretti V, Miłosz K (2018) Predictive analytics and disused railways requalification: insights from a post factum analysis perspective. Decis Support Syst 105:35-41

31. Chang YH, Wey WM, Tseng HY (2009) Using ANP priorities with goal programming for revitalization strategies in historic transport: a case study of the Alishan forest railway. Exp Syst Appl 36(4):8682-8690

32. Di Ruocco G, Sicignano E, Fiore P, D’Andria E (2017) Sustainable reuse of disused railway. Procedia Eng 180:1643-1652

33. Fan J (2015) Research on modern urban planning and construction of Zhangjiakou. Doctoral dissertation, Northern University of Technology

34. Zhang Y (2008) The rise and fall of Zhangjiakou commerce and the evolution of modern urban space. J Hebei North Univ 24(2):59-63

35. Dowall DE (1994) Urban residential redevelopment in the People's Republic of China. Urban Stud 31(9):1497-1516

36. He S, Wu F (2005) Property-led redevelopment in post-reform China: a case study of Xintiandi redevelopment project in Shanghai. J Urban Aff 27(1):1-23

37. Zhang Y, Fang K (2004) Is history repeating itself? From urban renewal in the United States to inner-city redevelopment in China. J Plann Educ Res 23(3):286-298

38. Jiyoon $S$ (2013) The economic impact of the preservation and adaptive reuse of rail tracks, the high line in New York City: regional impact analysis and property value change analysis. Doctoral dissertation, Cornell University

39. Zhai B, Wu M (2009) Urban renewal concept and urban reality in China. J Urban Plann 2:75-82

40. Wise D (1985) Urban regeneration. Construction 52:48-52

41. Li X, Yan W (2011) Analysis of China's railway development trend based on industrial life cycle theory. China Rail Sci 32(1):127-132 